\title{
Sodium pentobarbital and habituation-acquisition and transfer between states
}

\author{
SANDRA E. FILE* \\ MRC Unit of Neural Mechanisms of Behaviour, Department of Psychology, University College, London, England
}

\begin{abstract}
Subanesthetic doses of sodium pentobarbital impaired, but did not prevent, the acquisition of behavioral habituation. Animals habituated in a saline state showed transfer of habituation when later tested in a drugged condition. Animals habituated while drugged and then tested under saline conditions, showed much less transfer of habituation, and more rats showed state-dependent habituation as the drug dose during acquisition of habituation was increased.
\end{abstract}

The brainstem reticular formation (RF) has been constantly implicated in analyses of the neural mechanisms underlying habituation, although its precise role has varied from theory to theory (Hernandez-Péon, 1959; Mancia, Meulders, \& Santibanez, 1959a; Sokolov, 1960). Neurophysiological studies support this theoretical emphasis on the RF, since habituation in cells of the RF occurs with a time course similar to that of habituation of behavioral responses (e.g., Horn \& Hill, 1964; Bell, Sierra, Buendia, \& Segundo, 1964; Sokolov, 1966; Hirano, Best, \& Olds, 1970). Groves and Lynch (1972) have proposed a detailed model of how the RF is involved in habituation, but have primarily applied this model to short-term habituation, i.e., that occurring within a session, but not retained across days. Other brain areas, particularly the amygdala (Kimble, Bagshaw, \& Pribram, 1965) and hippocampus (Roberts, Dember, \& Brodwick, 1962; Green \& Adey, 1956; Bagshaw \& Benzies, 1968) have been implicated in long-term, or between-sessions, habituation. However, it has been suggested (Pribram, 1963) that it is the RF which mediates the hippocampal-amygdala involvement in habituation and, in similar vein, Groves and Lynch (1972) proposed that the effects following amygdalectomy, hippocampectomy, and decortication were secondary to the changes in reticular excitability caused by these lesions.

The main purpose of this experiment was to investigate the effects of sodium pentobarbital on habituation, and hence to test the hypothesis that the $\mathrm{RF}$ is involved in long-term habituation, since sodium pentobarbital has been shown to have primarily a reticular site of action (Hagbarth \& Kerr, 1954; Hagbarth \& Hojerberg, 1957; Hagberth \& Fex, 1959; Hernandez-Péon, Scherrer, \& Velasco, 1956). Anesthetic doses of sodium pentobarbital prevent the acquisition of habituation and abolish it in an animal previously

*Now at the Psychology Department, City of London Poly technic, Whitechapel High Street, London E1 7PF, England. This work was conducted while the author was in receipt of a Medical Research Council scholarship. She is grateful to H. C. Plotkin for a critical reading of the manuscript. habituated in a normal state (Hernandez-Péon, Jouvet, \& Scherrer, 1957; Mancia, Meulders, \& Santibanez, $1959 \mathrm{a}, \mathrm{b})$, but there is no evidence on the effect on behavioral habituation, nor on the acquisition of habituation under lower doses of the drug.

A secondary purpose of this experiment was to determine whether behavioral habituation was state-dependent when subanesthetic doses of sodium pentobarbital were used. In other words, would an animal, habituated in a normal state, remain habituated when tested under drugged conditions, and vice versa?

\section{METHOD}

\section{Subjects}

One hundred and twenty male hooded rats, $300-350 \mathrm{~g}$ in weight, were housed individually in a $12-\mathrm{h}$ light/12-h dark cycle with food available ad lib. The rats were water deprived for a period of $72 \mathrm{~h}$, and thereafter had daily access to water in the test chamber and immediately following an experimental session, in sufficient quantity to maintain a constant body weight.

\section{Apparatus}

The test chamber was $20.5 \mathrm{~cm}$ high with a grid floor, $34 \mathrm{x}$ $18 \mathrm{~cm}$, and was enclosed in an acoustically insulated refrigerator shell. The rat had access to a water spout through a slit, $3.5 \mathrm{x}$ $1 \mathrm{~cm}$, in the middle of the end wall of the chamber. A drinkometer recorded the rat's licking, and all experimental events were automatically programmed, using standard relay equipment. The source of tones was a Weinbridge oscillator which fed into a Sinclair amplifier and then to a loudspeaker (Wharfedale Super 3 Tweeter type), positioned on the lid of the test chamber. The tones used were $9 \mathrm{KHz}, 77.5 \mathrm{~dB}$ (re .0002 dynes $/ \mathrm{cm}^{2}$ ) for $5 \mathrm{sec}$.

\section{Procedure}

Prehabituation drinking sessions were given in the test chamber for 5 days, by which time all the rats started licking immediately on entering the chamber and continued without significant pause for at least $10 \mathrm{~min}$. During this period, none of the rats received any injection of drug or saline.

A pilot experiment (File, 1969) had been conducted to ascertain the uptake characteristics of the drug. After $72 \mathrm{~h}$ of water deprivation, followed by 5 days of prehabituation drinking sessions, 10 rats had received anesthetic doses of sodium 


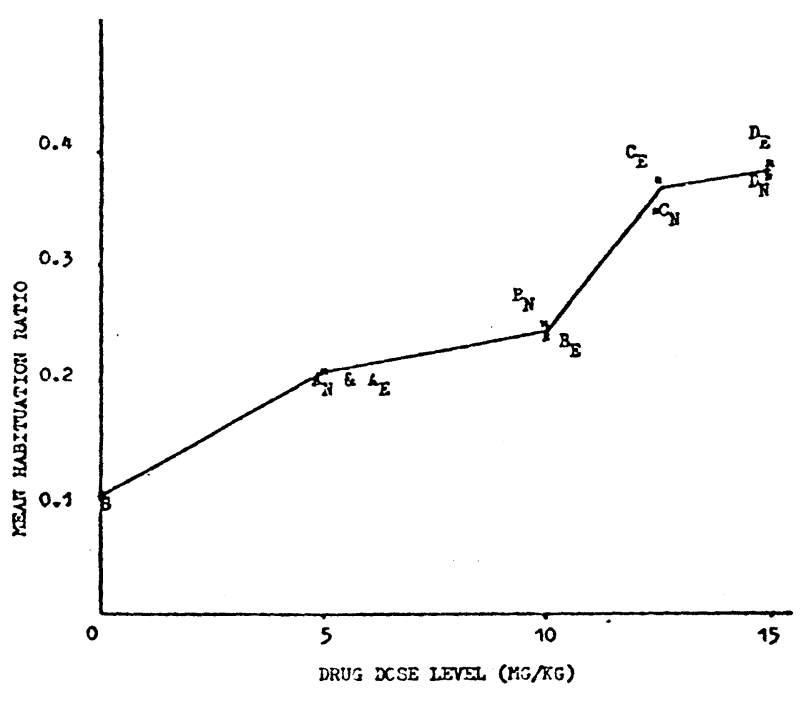

pentobarbital. The time at which the corneal reflex had disappeared was taken to represent the peak effect of the drug (Bowman, Rand, \& West, 1958). This ranged from 11 to $14 \mathrm{~min}$ after injection IP, with a mode of $13 \mathrm{~min}$. On the basis of these results, the rats were given access to water in their home cages $13 \mathrm{~min}$ after the drug or saline injections in Phase 1 of the experiment, and in Phase 2, they were placed in the test chamber 13 min after injection.

Twenty rats were randomly assigned to each of Groups A, B, $C$, and $D$, and 40 rats to Group $S$, and in Phase 1 of the experiment, they had 2 days on which they received an IP saline or drug (sodium pentobarbital injection, but did not enter the test chamber. Half of Groups A, B, C, and D received drug injections of $5,10,12.5$, and $15 \mathrm{mg} / \mathrm{kg}$, respectively; the other half and all of Group $S$ received saline. This procedure provided a control for previous experience of the drugged state. It was thought that on the very first occasion an animal was drugged, its attention might be focused on the consequent changes in internal stimuli. This would lead to poor performance in a habituation task because less attention was being paid to external events, rather than because the mechanism involved in habituation had been impaired.

The next day, in Phase 2 of the experiment, each rat received an IP injection-saline for Group $S$ and $5,10,12.5$, and $15 \mathrm{mg} / \mathrm{kg}$ for Groups A, B, C, and D, respectively-and $13 \mathrm{~min}$ later was placed in the test chamber. Ten tone presentations were given, at intervals of $1 \mathrm{~min}$, and then the rat was returned to its home cage. A record was kept of whether or not the rat was licking just prior to and during each tone presentation. This rapid stimulus presentation rate was necessary to ensure that the rats were not exposed to stimuli during the period of rapid drug loss.

The day following the tone presentations, the rats were tested for their levels of habituation, and this test constituted Phase 3 of the experiment. They were given IP injections of saline or drug as on the previous day, and $13 \mathrm{~min}$ later placed in the test chamber. On this occasion, the rat's 200th lick switched on a control period of $5 \mathrm{sec}$ in which the number of licks was counted. Following this period, the next 200th lick switched on the tone stimulus for $5 \mathrm{sec}$, and the number of licks during this presentation were recorded. Since rats lick at a constant rate of 7 laps/sec, there was no change in the base-lick rate during the test session, and after 5 days of prehabituation training, the animals would lick for $10 \mathrm{~min}$ without pause, in the absence of any tone stimuli. It should therefore be unnecessary to balance the order of presentation of control and tone periods and, indeed, pilot experiments (File, 1969) confirmed this point. After receiving only one test tone presentation, the rats were returned to their home cages.

In order to accommodate any brief pauses in licking that might have occurred in the absence of any stimuli, a habituation ratio was adopted as the measure of habituation. This ratio was the difference between the number of licks in the control and tone periods divided by the number of licks in the control period. Thus, a ratio of zero would reflect complete habituation and exactly the same number of licks in the control and tone periods, whereas a ratio of one would reflect complete distraction and cessation of licking during the tone presentation. Habituation ratios were calculated for the test tone presentation and, on the basis of these, some animals proceeded to Phase 4 of the experiment. This was a test to determine the extent to which habituation was state-dependent, and therefore animals from Group $S$ were now tested under drugged conditions and animals from the four drug groups were now tested under saline conditions. Since the transfer of habituation was under investigation, and because of difficulties in interpreting transfer data when the initial level of habituation is poor, only rats with habituation ratios $\leqslant .50$ were tested.

The following day all the rats in Groups A, B, C, and D which qualified for Phase 4 of the experiment, the transfer test, received an IP saline injection and 13 min later were placed in the test chamber. Once again the rat's 200th lick switched on a control period of $5 \mathrm{sec}$ in which the number of licks was counted. After this period, the next 200th lick switched on the tone for $5 \mathrm{sec}$ and again the number of licks was recorded. Habituation ratios were then calculated for this test presentation under saline conditions. Thirty-eight of 40 animals in Group S qualified for the transfer test, and therefore 10 rats were randomly assigned to each of the drug dose levels of 5 and $15 \mathrm{mg} / \mathrm{kg}$ and 9 to each of the 10 and $12.5 \mathrm{mg} / \mathrm{kg}$ dose levels. Injections of the appropriate dose level were given IP, and $13 \mathrm{~min}$ later the rats were placed in the test chamber and a single tone presentation given as before. Habituation ratios were calculated for each of the four dose level groups.

\section{RESULTS}

Phase 1 of the experiment had involved a prehabituation experience of the drug or saline. Phase 2 had consisted of 10 stimulus presentations to animals in a drugged or saline condition, and in Phase 3 one tone presentation was given in the same drugged or saline condition, to test for the level of habituation. Figure 1 shows the mean habituation ratios to this test tone for Groups S, A, B, C, and D, reflecting the level of acquisition of habituation under saline-conditions and under each of the drug dose levels. In Fig. 1, the ratios have been marked separately for the rats which had no prehabituation experience of the drug (i.e., which had saline in Phase 1 of the experiment $-A_{N}, B_{N}, C_{N}$, and $D_{N}$ ) and for those with the prehabituation drug experience in Phase $1\left(A_{E}, B_{E}, C_{E}\right.$, and $\left.D_{E}\right)$. From this figure, it is clear that the prior drug experience in Phase 1 had no effect on the acquisition of habituation in Phase 2, and therefore in each group, the scores from the two Phase 1 conditions were combined and the combined means plotted graphically.

From Fig. 1, it can be seen that the saline group showed greater habituation (i.e., a smaller habituation ratio) than the drug groups, and that as the dose level 
was increased, so the amount of habituation decreased. The impairment in habituation resulting even from the lowest level of drug was significant $(t=2.12, \mathrm{df}=58$, $\mathrm{p}<.05$ ), and the increase in impairment as the dose level was increased was also significant $(\mathrm{t}=2.03, \mathrm{df}=38$, $\mathrm{p}<.05$, comparing Groups A and D).

Since there is seldom complete identity in the number of licks, even in two control periods, a criterion of habituation had been adopted in previous experiments (e.g., File \& Russell, 1972) of a ratio $\leqslant .05$. Table 1 gives the percentage of rats in each group which was at habituation criterion when presented with the test stimulus. From this it can be seen that as the drug dose level was increased, so there was a decrease in the number of rats at habituation criterion after 10 stimulus presentations. Table 1 also gives the percentage of animals in each group showing no habituation at all (i.e., a ratio of 1.0) after 10 stimulus presentations. Only with a dose of at least $10 \mathrm{mg} / \mathrm{kg}$ was habituation completely absent in some rats. Therefore, in general, sodium pentobarbital acted to impair the rate of habituation, so that the higher the dose the greater the habituation ratio after 10 tone presentations, but some of this effect was due to an increased number of rats showing no habituation at all. However, it cannot be concluded that habituation was completely blocked in these cases, since it is possible that some habituation would have occurred with a greater number of stimulus presentations.

Finally, Table 1 shows the percentage of rats in each group qualifying for Phase 4 of the experiment, i.e., the test of state-dependent habituation. A ratio of $\leqslant .50$ had been chosen as the criterion for proceeding to this test, and represents a stage part way to habituation criterion. The effect of an increase in drug dose was to decrease the number of rats reaching this stage, but even in Groups C and D, this left 13 rats to be tested under saline conditions. Comparisons of the amount of transfer occurring between states for the various groups would be valid only if all the groups had been at the same level of habituation prior to the transfer test. A $5 \times 1$ analysis of variance was therefore carried out on the habituation ratios for the rats that proceeded to the transfer test, and this showed no significant difference in the level of habituation between the various groups $(F=1.6, \mathrm{df}=$ $4,91, p>.05)$. The mean ratios to the test stimulus in the drug conditions, for only the animals proceeding to the transfer test, were $0.11,0.08,0.11$, and 0.13 for Groups A, B, C, and D, respectively. When tested under saline conditions, the mean ratio for Group A was 0.30 , for Group B 0.54, for Group C 0.74, and for Group D 0.69 . For each individual rat, if the ratio when tested in a saline condition was $\geqslant$ the ratio when previously tested in the drugged condition, then this was taken as evidence of complete transfer of habituation between states. Fifty percent of rats in Group A, 31\% in Group B, 8\% in Group C, and 15\% in Group D showed complete transfer of habituation from a drugged to a saline state. Saline ratios of 1.0 were taken as reflecting state-dependent
Table 1

Level of Habituation After 10 Tone Presentations

\begin{tabular}{lccccc}
\hline & \multicolumn{5}{c}{ Group } \\
\cline { 2 - 6 } & S & A & B & C & D \\
\hline $\begin{array}{l}\text { Percent Rats } \\
\text { at Criterion }\end{array}$ & 70 & 50 & 40 & 35 & 30 \\
$\begin{array}{l}\text { Percent Rats } \\
\text { Ratios } \leqslant .50\end{array}$ & 95 & 80 & 80 & 65 & 80 \\
$\begin{array}{l}\text { Percent Rats } \\
\text { Showing No } \\
\text { Habituation }\end{array}$ & 0 & 0 & 15 & 20 & 20 \\
\hline
\end{tabular}

habituation. This may seem a strict criterion, since not all animals have a ratio of 1.0 , even on their very first stimulus presentation. However, in previous studies (e.g., File, 1973a), the mean ratio to the first stimulus presentation ranged from 0.99 to 0.90 , and certainly a ratio of $<.80$ from an individual animal would be unusual in response to the first stimulus presentation. Looking at the individual scores and excluding ratios of 1.0 , the highest habituation ratio in the transfer test was 0.74. Therefore, in this particular case, only counting animals with ratios of 1.0 as showing state-dependent habituation was unlikely to have biased the results. Using this criterion, $12.5 \%$ of Group A, $44 \%$ of Group B, $54 \%$ of Group C, and $62 \%$ of Group D showed state-dependent habituation. All the rats with a saline ratio greater than the drug ratio but less than 1.0 were considered to show partial transfer of habituation-37.5\% in Group A, 25\% in Group B, 38\% in Group C and 23\% in Group D.

Similar comparisons were made between the saline ratios for rats in Group $S$ and the ratios when tested under one of the drug doses. In contrast to the previous transfer results, these comparisons reflect a high level of transfer even when tested at the largest dose level. Complete transfer was shown by $80 \%$ of rats tested under $5 \mathrm{mg} / \mathrm{kg}$ of drug, $67 \%$ of rats tested under 10 and $12.5 \mathrm{mg} / \mathrm{kg}$, and $60 \%$ of rats tested under the highest dose of $15 \mathrm{mg} / \mathrm{kg}$. No more than one animal at each dose level in the transfer test showed state-dependent habituation. The only difference between the various dose levels was a shift from complete to partial transfer as the dose level increased.

\section{DISCUSSION}

As long as a rat had been licking just prior to the tone onset or during the tone, it was assumed that the animal had been in a constant position for each stimulus presentation. From the records of licking made during the tone presentations, it was found that only 2 out of the 120 rats had not been in a constant position for at least 9 out of the 10 presentations. Both these rats were in the saline group and may have been in a different position for three of the presentations. If the rat's position had varied from trial to trial, it would have been 
exposed to a range of stimuli, varying at least in intensity, and this would have invalidated comparisons of the level of habituation between animals. The rate of licking (in the absence of any tones) remained normal in all groups, i.e., about 7 laps/sec, and therefore the administration of sodium pentobarbital did not alter the rate of base-line responding.

There were two reasons for testing the level of habituation $24 \mathrm{~h}$ after the series of stimulus presentations. First, Ison and Hammond (1971) had demonstrated inhibition of a startle response to a stimulus by the presentation of a preceding stimulus ("prepulse inhibition"). In habituation experiments using short interstimulus intervals, the response decrement could be the joint result of prepulse inhibition and habituation. Secondly, Davis (1970) suggested that the interstimulus interval should not be confounded with the interval between the end of training and testing. A short interstimulus interval was necessary in this experiment to enable 10 tones to be presented before the drug effects diminished, but testing $24 \mathrm{~h}$ later gave a response measure free from any effects of prepulse inhibition or the coufounding of the interstimulus interval and the interval before testing. In an experiment on the effect of various interstimulus intervals on the rate of habituation (File, 1973b), the mean habituation ratio after 10 presentations of a 5 -sec tone at an interstimulus interval of $1 \mathrm{~min}$ was 0.12 . In this experiment, the mean ratio for the saline group was 0.10 , which suggests that their rate of habituation was entirely typical of previous results.

The control for the previous experience of the drug proved unnecessary in this experiment. Apparently, the rats had not been attending to internal stimulus changes to the detriment of their habituation performance. However, it is possible that, at higher dose levels, the rats would have attended more to internal changes, and certainly this control should not be omitted from other experiments on the basis of the negative results reported here.

This experiment has demonstrated that the acquisition of habituation is impaired by subanesthetic doses of sodium pentobarbital-the higher the dose, the greater the impairment. Since testing took place $24 \mathrm{~h}$ after the stimulus presentations, the results of this study are applicable to long-term habituation. It would therefore seem likely that the RF is involved in the acquisition of long-term habituation, as well as being involved in short-term habituation, as previously suggested (Groves \& Lynch, 1972). Previous experiments had not studied the original acquisition of habituation under a drugged state. They habituated the animal while in a normal state, found dishabituation under barbiturate anesthesia, and then reported no rehabituation in this state (Hernandez-Peón, 1960, 1961; Hernandez-Peón \& Brust-Carmona, 1961). However, they gave too few stimulus presentations in this drugged state to be able to conclude whether habituation was totally prevented or only greatly slowed down, but either conclusion would be compatible with the results of the present experiment. Mancia et al (1959a) criticized the interpretation of the results from experiments using anesthetic doses of pentobarbital, because with large doses brain structures other than reticular ones may have been suppressed. It is less likely that this criticism would apply to the dose levels used in this study.

There is ample evidence in the literature that habituation is state-dependent when the animal is habituated in a normal state and then tested under deep barbiturate anesthesia (Hernandez-Peón, 1960, 1961; Gershuni et al, 1960; Hernandez-Peón \& Scherrer, 1955; Hernandez-Peón \& Brust-Carmona, 1961). There is also some evidence of transfer of habituation from normal to subanesthetic (as opposed to anesthetic) doses of sodium pentobarbital (Hernandez-Peón, Jouvet, \& Scherrer, 1957; Mancia et al, 1959a, b). The results from this experiment are quite consistent with these earlier reports on subanesthetic doses. There was no evidence in the literature on the transfer of habituation from a drug to a normal state. In this experiment, only $50 \%$ of the rats showed complete transfer of habituation, even from the lowest dose level of drug. In going from saline to drug or vice versa, the decreasing transfer found as the dose level was increased is explicable in terms of an increased stimulus change between the saline and drug states.

What is less readily explained is the overall greater transfer oî habituation when going from saline to drug states than when going from a drug to a saline state. However, it is not impossible to explain this result on the basis of existing theories of learning. For example, one explanation can be advanced through an extension of Estes's stimulus sampling theory of drive states (Estes, 1958) to drug states. On the basis of his theory, Estes predicts greater transfer when training is under no- or low-drive conditions and testing under a high-drive condition, than vice versa. This asymmetry in transfer is a necessary consequent of the assumption that there are more stimulus elements associated with deprivation than there are in the set associated with satiation. If a similar assumption is made of more stimulus elements associated with a drug state than with a saline state, then the transfer results obtained in this experiment would be predicted. At this stage, no more than this initial suggestion can be made as to how stimulus sampling theory might be applied to this experimental situation. There are too many unknown factors for a complete application of the theory-for example, does the drug affect the number of stimulus elements sampled on any one trial?

\section{REFERENCES}

Bagshaw, M., \& Benzies, S. Multiple measures of the orienting reaction and their dissociation after amygdalectomy in monkeys. Experimental Neurology, 1968, 20, 175-187.

Bell, C., Sierra, G. Buendia, N., \& Segundo, J. Sensory properties of neurons in the mesencephalic reticular 
formation. Journal of Neurophysiology, 1964, 27, 951-987.

Bowman, W., Rand, N., \& West, G. Textbook of pharmacology. London: Blackwell, 1968.

Davis, M. Effects of ISI length and variability on startle response habituation in rat. Journal of Comparative \& Physiological Psychology, 1970, 72, 177-192.

Estes, W. Stimulus-response theory of drive. In M: R. Jones (Ed.), Nebraska symposium on motivation. Lincoln: University of Nebraska Press, 1958. Pp. 35-69.

File, S. Habituation-a parametric study of the behavioural phenomenon. Unpublished University of London PhD thesis, 1969.

File, S. Effects of stimulus duration and intensity on the rate and specificity of behavioural habituation. Quarterly Journal of Experimental Psychology, 1973a, 25, 96-103.

File, S. Interstimulus interval and the rate of behavioural habituation. Quarterly Journal of Experimental Psychology, $1973 \mathrm{~b}, 25,360-367$.

File, S., \& Russell, I. Specificity and savings of behavioural habituation over a series of intra- and inter-model stimuli. Quarterly Journal of Experimental Psychology, 1972, 24, 465-473.

Gershuni, G., Kozhevnikov, V., Maruseva, A., Avakyan, R., Radionova, E., Altman, J., \& Soroko, V. Modifications in electrical responses of the auditory system in different states of the higher nervous activity. Electroencephalography \& Clinical Neurophysiology Supplement, 1960, Supplement 13, 115-124.

Green, J., \& Adey, W. Electrophysical studies of hippocampal connections and excitability. Electroencephalography \& Clinical Neurophysiology, 1956, 8, 245-262.

Groves, P., \& Lynch, G. Mechanisms of habituation in the brain stem. Psychological Review, 1972, 79, 237-244.

Hagbarth, K., \& Fex, J. Centrifugal influences on single unit activity in spinal sensory paths. Journal of Neurophysiology, 1959, 22, 329-338.

Hagbarth, K., \& Hojerberg, S. Evidence for subcortical regulation of the afferent discharge to the somatic sensory cortex in man. Nature, 1957, 179, 526-527.

Hagbarth, K., \& Kerr, D. Central influences on spinal afferent conduction. Journal of Neurophysiology, 1954, 18, 388-411.

Hernandez-Peón, R. Centrifugal control of sensory inflow to the brain and sensory perception. Acta Neurologica Latino America, 1959, 5, 279-298.

Hernandez-Peón, R. Neurophysiological aspects of habituation. In Moscow Symposium, Electroencephalography \& Clinical Neurophysiology Supplement, 1960, Supplement 13, 104-114.

Hernandez-Peón, R. Reticular mechanisms of sensory control. In W. Rosenblith (Ed.), Sensory communication. Cambridge, Mass: M.I.T. Press, 1961. Pp. 497-520.

Hernandez-Peón, R., \& Brust-Carmona, H. Functional role of subcortical structures in habituation and conditioning. In
Brain mechanisms and learning. CIOMS Symposium, 1961. Pp. 393-412.

Hernandez-Peón, R., Jouvet, M., \& Scherrer, H. Auditory potentials at the cochlear nucleus during acoustic habituation. Acta Neurological Latino America, 1957, 3, 144-156.

Hernandez-Peón, R., \& Scherrer, H. Habituation to acoustic stimuli in cochlear nucleus. Federation Proceedings, 1955, 14, 71.

Hernandez-Peón, R., Scherrer, H., \& Velasco, M. Central influences of afferent conduction in somatic and visual pathways. Acta Neurologica Latino America, 1956, 2, 8-28.

Hirano, T., Best, B., \& Olds, J. Units during habituation, discrimination learning and extinction. Electroencephalography \& Clinical Neurophysiology, 1970, $28,127-135$.

Horn, G., \& Hill, R. Habituation of the response to sensory stimuli of neurons in the brainstem of rabbits. Nature, 1964, 202, 296-298

Ison, J., \& Hammond, G. Modification of the startle reflex in the rat by changes in the auditory and visual environments. Journal of Comparative \& Physiological Psychology, 1971, 75, 435-452.

Kimble, D., Bagshaw, M., \& Pribram, K. The GSR of monkeys during orienting and habituation after selective partial ablations of cingulate and frontal cortex. Neuropsychologia, 1965, 3, 121-128.

Mancia, M., Meulders, M., \& Santibanez, G. Changes of photically evoked potentials in visual pathway of cerveau isole cat. Archives Italiennes de Biologie, 1959a, 97, 378-398.

Mancia, M., Meulders, M., \& Santibanez, G. Changes of photically evoked potentials in the visual pathway of the midpontine pretrigeminal cat. Archives of Italiennes de Biologia, 1959b, 97, 399-413.

Pribram, K. Reinforcement revisited: A structural view. In M. R. Jones (Ed.), Nebraska symposium on motivation. Lincoln: University of Nebraska Press, 1963.

Roberts, W., Dember, W., \& Brodwick, M. Alternation and exploration in rats with hippocampal lesions. Journal of Comparative \& Physiological Psychology, 1962, 55, 695-704.

Sokolov, E. Neuronal models and the orienting reflex. In M. A. Brazier (Ed.), CNS and behavior. Vol. 3. New York: Macy, 1960. Pp. 187-276.

Sokolov, E. Neuronal mechanisms of the orienting reflex. Eighteenth International Congress of Psychology. Moscow Symposium on Orienting Reflex, Alertness \& Attention, 1966, 31-36.

Stellar, E., \& Hill, J. The rat's rate of drinking as a function of water deprivation. Journal of Comparative \& Physiological Psychology, 1952, 45, 96-102.

(Received for publication January 18, 1973; revision received August 24, 1973.) 